\title{
IoT for Healthcare
}

\author{
B. Sobhan Babu ${ }^{1}$, K. Srikanth ${ }^{2}$, T. Ramanjaneyulu ${ }^{3}$, I. Lakshmi Narayana ${ }^{4}$ \\ ${ }^{1,2,3,4}$ Gudlavalleru Engineering College, Gudlavalleru. Krishna District, Andhra Pradesh, India
}

\begin{abstract}
The Internet of Things (IoT) is the network of physical objects or things embedded with electronics, software, sensors, and network connectivity, which enables these objects to collect and exchange data. The Internet of Things allows objects to be sensed and controlled remotely across existing network infrastructure. The IoT is enabled by the latest developments in RFID, smart sensors, communication technologies, and Internet protocols. The basic premise is to have smart sensors collaborate directly without human involvement to deliver a new class of applications. The current revolution in Internet, mobile, and machine-to-machine (M2M) technologies can be seen as the first phase of the IoT. In the coming years, the IoT is expected to bridge diverse technologies to enable new applications by connecting physical objects together in support of intelligent decision making. Smart healthcare plays a significant role in healthcare applications through embedding sensors and actuators in patients and their medicine for monitoring and tracking purposes. The IoT is used by clinical care to monitor physiological statuses of patients through sensors by collecting and analyzing their information and then sending analyzed patient's data remotely to processing centers to make suitable actions. Not only for patients, it also useful for normal people to check the health status by using wearable devices with sensors.
\end{abstract}

Keywords: IOT, RFID, Internet Protocols, M2M, SBC.

\section{Introduction}

Internet of Things (IoT) is an ideal emerging technology to influence the internet and communication technologies. Simply Internet of Things" connects living and nonliving things" through ,internet”. Traditionally in the object oriented paradigm everything in the world is considered as an object, but in the IoT paradigm everything in the world is considered as a smart object, and allows them to communicate each other through the internet technologies by physically or virtually. IoT allows people and things to be connected Anytime, Anyplace, with anything and anyone, by using ideally in any path/network and any service. Every day the modern people expect new device and new technology to simplify their day to day life. The innovators and researchers are always trying to find new things to satisfy the people but the process is still infinite. In the 1990s, Internet connectivity began to proliferate in enterprise and consumer markets, but was still limited in its use because of the low performance of the network interconnects. In the 2000s Internet connectivity became the norm for many applications and today is expected as part of many enterprise, industrial and consumer products to provide access to information. However, these devices are still primarily things on the Internet that require more human interaction and monitoring through apps and interfaces. One research reveals, the Internet of Things (IoT), which excludes PCs, tablets and smart phones, will grow to 26 billion units installed in 2020 representing an almost 30-fold increase from 0.9 billion in 2009. This paper contains four modules introduction of IOT, RFID, protocols in IOT and how IOT is useful in health care. This paper contains total five modules introduction of IoT, about RFID, Protocols of IoT, Health Care using IoT, Devices used with IoT and then conclusion.

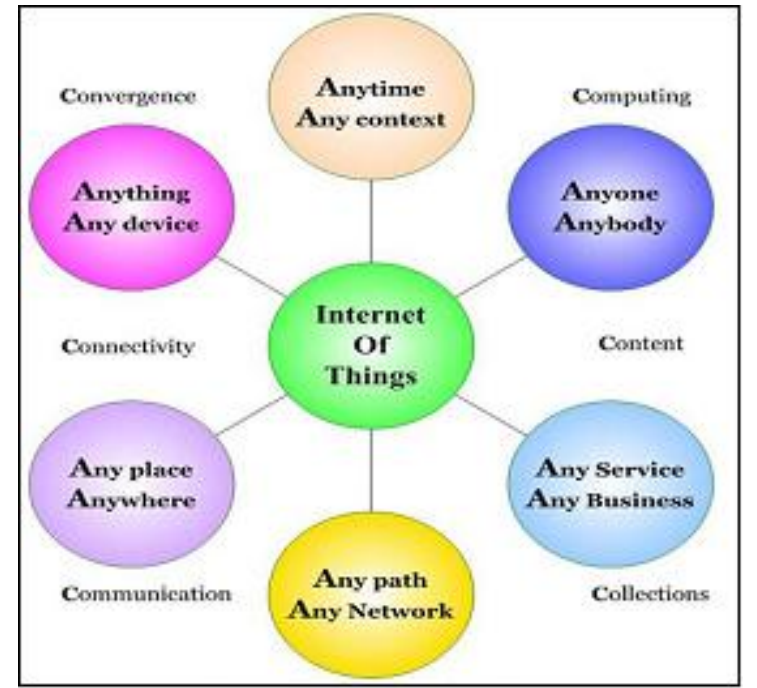

Figure 1: Objectives of IoT

\section{Radio-frequency identification (RFID)}

It was seen as a prerequisite for the Internet of Things in the early days. If all objects and people in daily life were equipped with identifiers, they could be managed and inventoried by computers. Besides using RFID, the tagging of things may be achieved through such technologies as near field communication, barcodes, QR codes, Mobile Computing, Ambient Intelligence. The RFID tag represents a simple chip or label attached to provide object's identity. The RFID reader transmits a query signal to the tag and receives reflected signal from the tag, which in turn is passed to the database. The database connects to a processing center to identify objects based on the reflected signals within a (10 $\mathrm{cm}$ to $200 \mathrm{~m}$ ) range. RFID tags can be active, passive or semi-passive/active. Active tags are powered by battery while passive ones do not need battery. Semi-passive/active tags use board power when needed. Active RFID readers have their own battery supply and can instantiate the communication. RFID is the first technology used to realize the M2M concept (RFID tag and reader). The RFID reader transmits a query signal to the tag and receives reflected 


\section{International Journal of Science and Research (IJSR) \\ ISSN (Online): 2319-7064}

Index Copernicus Value (2013): 6.14 | Impact Factor (2014): 5.611

signal from the tag, which in turn is passed to the database. The database connects to a processing center to identify objects based on the reflected signals within a $(10 \mathrm{~cm}$ to $200 \mathrm{~m})$ range.

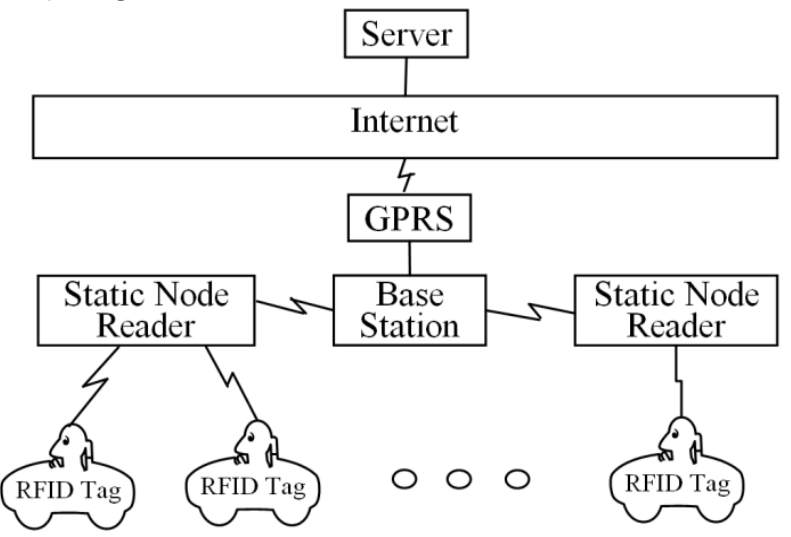

Figure 2: RFID-based sensor network

\section{Protocols in IOT}

\subsection{Constrained Application Protocol (CoAP)}

The IETF Constrained RESTful Environments (CoRE) working group created CoAP, which is an application layer protocol for IoT applications. The CoAP defines a web transfer protocol based on REpresentational State Transfer (REST) on top of HTTP functionalities. REST represents a simpler way to exchange data between clients and servers over HTTP. REST can be seen as a cacheable connection protocol that relies on stateless client-server architecture. It is used within mobile and social network applications and it eliminates ambiguity by using HTTP get, post, put, and delete methods. REST enables clients and servers to expose and consume web services like the Simple Object Access Protocol (SOAP) but in an easier way using Uniform Resource Identifiers (URIs) as nouns and HTTP get, post, put, and delete methods as verbs.

\subsection{Message Queue Telemetry Transport (MQTT)}

MQTT is a messaging protocol that was introduced by Andy Stanford-Clark of IBM and Arlen Nipper of Arcom (now Eurotech) in 1999 and was standardized in 2013 at OASIS [70].MQTT aims at connecting embedded devices and networks with applications and middleware. The connection operation uses a routing mechanism (one-to-one, one-tomany,many-to-many) and enables MQTT as an optimal connection protocol for the IoT and M2M.

\subsection{Extensible Messaging and Presence Protocol (XMPP)}

XMPP is an IETF instant messaging (IM) standard that is used for multi-party chatting, voice and video calling and telepresence. XMPP was developed by the Jabber open source community to support an open, secure, spam free and decentralized messaging protocol. XMPP allows users to communicate with each other by sending instant messages on the Internet no matter which operating system they are using. XMPP allows IM applications to achieve authentication, access control, privacy measurement, hop-by-hop and end-toend encryption, and compatibility with other protocols.

\subsection{Advanced Message Queuing Protocol (AMQP)}

AMQP [75] Is an open standard application layer protocol for the IoT focusing on message-oriented environments? It supports reliable communication via message delivery guarantee primitives including at-most-once, at-least-once and exactly once delivery. AMQP requires a reliable transport protocol like TCP to exchange messages.

\subsection{LowPAN}

Low power Wireless Personal Area Networks (WPANs) which many IoT communications may rely on have some special characteristics different from former link layer technologies like limited packet size (e.g., maximum 127 bytes for IEEE 802.15.4), various address lengths, and low bandwidth [89]-[91]. So, there was a need to make an adaptation layer that fits IPv6 packets to the IEEE 802.15.4 specifications. The IETF 6LoWPAN working group developed such a standard in 2007. 6LoWPAN is the specification of mapping services required by the IPv6 over Low power WPANs to maintain an IPv6 network [89]. The standard provides header compression to reduce the transmission overhead, fragmentation to meet the IPv6 Maximum Transmission Unit (MTU) requirement, and forwarding to link-layer to support multi-hop delivery.

\subsection{Z-Wave}

Z-Wave as a low-power wireless communication protocol for Home Automation Networks (HAN) has been used widely in the remote control applications in smart homes as well as small-size commercial domains [101]. This protocol was initially developed by ZenSys (currently Sigma Designs) and later was employed and improved by Z-Wave Alliance. ZWave covers about 30 meters point-to-point communication and is specified for applications that need tiny data transmission like light control, household appliance control, smart energy and HVAC, access control, wearable health care control, and fire detection. Z-Wave operates in ISM bands (around $900 \mathrm{MHz}$ ) and allows transmission rate of 40 kbps. The recent versions also support up to $200 \mathrm{kbps}$. Its MAC layer benefits from a collision avoidance mechanism. Reliable transmission is possible in this protocol by optional ACK messages.

\section{Health Care}

Smart healthcare plays a significant role in healthcare applications through embedding sensors and actuators in patients and their medicine for monitoring and tracking purposes. The IoT is used by clinical care to monitor physiological statuses of patients through sensors by collecting and analyzing their information and then sending analyzed patient's data remotely to processing centers to make suitable actions. For example, Masimo Radical-7 monitors the patient's status remotely and reports that to a clinical staff. Recently, IBM utilized RFID technology at one 


\section{International Journal of Science and Research (IJSR) \\ ISSN (Online): 2319-7064}

Index Copernicus Value (2013): 6.14 | Impact Factor (2014): 5.611

of OhioHealth's hospitals to track hand washing after checking each patient. That operation could be used to avoid infections that cause about 90000 deaths and losing about $\$ 30$ billion annually. Generally in the case of accidents someone has must intimate to the hospital for getting ambulance, but in the case of IoT whenever accidents are takes place, the wearable devices automatically gives signal to nearest Wi-Fi router and then hospitals to get the ambulance, based upon her health conditions like heartbeats.

IoT can be used to supplement patient treatment through remote monitoring and communication, and to keep track of patients as they move through a healthcare facility. Read on to discover the specifics of these IoT deployments.

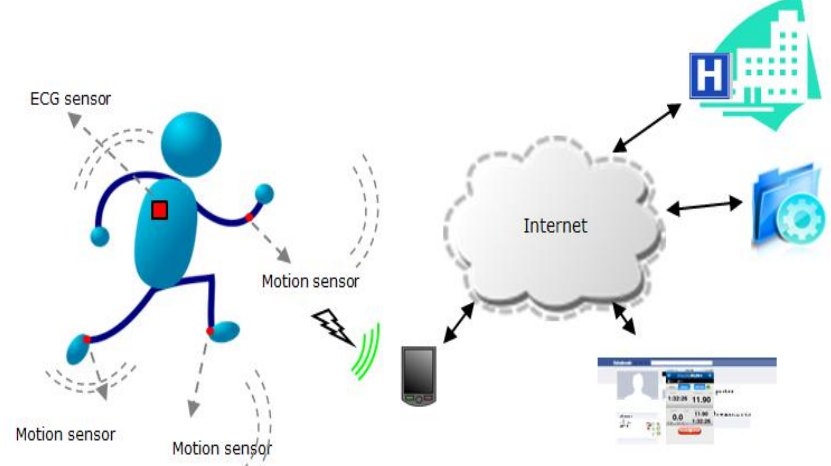

Figure 3: Helathcare using IoT

Hospitalized patients whose physiological status requires close attention can be constantly monitored using IoT-driven, noninvasive monitoring. This type of solution Employs sensors to collect comprehensive physiological information and uses gateways and the cloud to analyze and store the information and then send the analyzed data wirelessly to caregivers for further analysis and review. It replaces the process of having a health professional come by at regular intervals to check the patient's vital signs, instead providing a continuous automated flow of information. In this way, it simultaneously improves the quality of care through constant attention and lowers the cost of care by eliminating the need for a caregiver to actively engage in data collection and analysis. There are people all over the world whose health may suffer because they don't have ready access to effective health monitoring. But small, powerful wireless solutions connected through the IoT are now making it possible for monitoring to come to these patients instead of vice-versa. These solutions can be used to securely capture patient health data from a variety of sensors, apply complex algorithms to analyze the data and then share it through wireless connectivity with medical professionals who can make appropriate health recommendations.

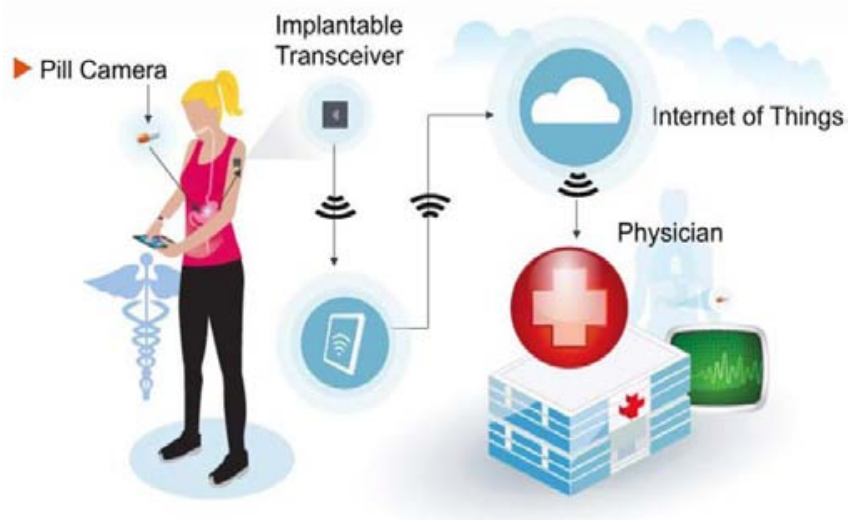

Figure 5: Remote Patient Monitoring

Smart sensors, which combine a sensor and a microcontroller, make it possible to harness the power of the IoT for healthcare by accurately measuring, monitoring and analyzing a variety of health status indicators. These can include basic vital signs such as heart rate and blood pressure, as well as levels of glucose or oxygen saturation in the blood. Smart sensors can even be incorporated into pill bottles and connected to the network to indicate whether a patient has taken a scheduled dose of medication.

\section{IoT Hardware Devices}

Different types of Single Board Computers (SBCs) integrated with sensors and built-in TCP/IP and security functionalities are typically used to realize IoT products (e.g., Arduino Yun, Raspberry PI, Beagle Bone Black, etc.). Such devices typically connect to a central management portal to provide the required data by customers. One of the key learning platforms for IoT is the Raspberry Pi. The RasPi is a popular platform because it offers a complete Linux server in a tiny platform for a very low cost. In fact, one of the most difficult parts of using Raspberry Pi for learning about IoT is picking the right projects with which to begin. The following figure shows the view of Raspberry Pi 2 - MODB.

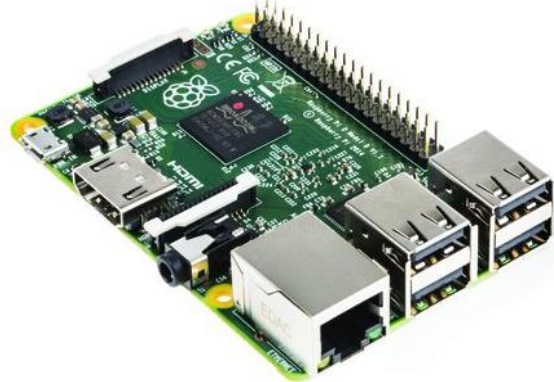

Figure 4: Raspberry Pi 2 - MODB

Windows 10 IoT Core is a new edition of Windows targeted towards small embedded devices and maker boards such as Raspberry Pi2. IoT core is designed to work with low-level bus interfaces such as I2C, SPI, and USB. You can write a Universal Windows Application using a variety of programming languages in Visual Studio to rapidly create maker projects. You can use Windows 10 IoT Core to read sensor data, control actuators, connect to the cloud, create IoT applications and much more. The Starter Pack from Adfruit includes parts to get you started. Some other boards 


\section{International Journal of Science and Research (IJSR) \\ ISSN (Online): 2319-7064}

Index Copernicus Value (2013): 6.14 | Impact Factor (2014): 5.611

are also available to perform IoT operations; those are PanStamps, TinyDuino, RFDuino, Intel Edision, UDOO etc.

\section{Conclusion}

In summary, one vision of the future is that IoT becomes a utility with increased sophistication in sensing, actuation, communications, control, and in creating knowledge from vast amounts of data. This will result in qualitatively different lifestyles from today. What the lifestyles would be is anyone's guess. It would be fair to say that we cannot predict how lives will change. We did not predict the Internet, the Web, social networking, Facebook, Twitter, millions of apps for smartphones, etc., and these have all qualitatively changed societies` lifestyle. Especially for healthcare system, it is most useful to every human. So health problems are easily predicted at the beginning stage based on IoT healthcare system.

\section{References}

[1] D. Evans, The Internet of things: How the next evolution of the Internet is changing everything,"CISCO, San Jose,CA, USA, White Paper, 2011.

[2] L. Atzori, A. Iera, and G. Morabito, The Internet of Things: A survey," Comput. Netw., vol. 54, no. 15, pp. 2787-2805, Oct. 2010.

[3] N. Kushalnagar, G. Montenegro, and C. Schumacher, Hv6 over Low- Power Wireless Personal Area Networks (6LoWPANs): Overview, assumptions, problem statement, and goals," Internet Eng. Task Force (IETF), Fremont, CA, USA, RFC4919, vol. 10, Aug. 2007.

[4] R. Want, -Anintroduction to RFID technology," IEEE Pervasive Comput., vol. 5, no. 1, pp. 25-33, Jan.-Mar. 2006.

[5] C. Nay, Sensors remind doctors to wash up," IBM Res., Armonk, NY, USA, 2013.

[6] K. Michaelsen, J. L. Sanders, S. M. Zimmer, and G. M. Bump, Đvercoming patient barriers to discussing physician hand hygiene: Do patients prefer electronic reminders to other methods?" Infection Control, vol. 34, no. 9, pp. 929-934, Sep. 2013.

[7] S. Jain et al., - Alow-cost custom HF RFID system for hand washing compliance monitoring," in Proc. IEEE 8th ASICON, 2009, pp. 975-978.

[8] T. Kamiya and J. Schneider, Efficient XML Interchange (EXI) Format 1.0," World Wide Web Consortium, Cambridge, MA, USA, Recommend. RECExi-20110310, 2011.

[9] D. Locke, MQ telemetry transport (MQTT) v3.1 protocol specification," IBM developerWorks, Markham, ON, Canada, Tech. Lib., 2010. [Online]. Available: $\quad$ Http://Www.Ibm.Com/Developerworks/ Webservices/Library/Ws-Mqtt/Index.Html

[10] U. Hunkeler, H. L. Truong, and A. Stanford-Clark, MQTT-S - A publish/subscribe protocol for wireless sensor networks," in Proc. $3^{\text {rd }}$ Int. Conf. COMSWARE, 2008, pp. 791-798.

[11]P. Saint-Andre, Extensible messaging and presence protocol (XMPP): Core," Internet Eng. Task Force
(IETF), Fremont, CA, USA, Request for Comments: 6120, 2011.

[12]E. C. Jones and C. A. Chung, RFID and Auto-ID in Planning and Logistics: A Practical Guide for Military UID Applications. Boca Raton, FL, USA: CRC Press, 2011.

[13]D. Minoli, Building the Internet of Things With IPv6 and MIPv6: The Evolving World of M2M Communications. New York, NY, USA: Wiley, 2013.

[14]D. Uckelmann, Performance measurement and cost benefit analysis for RFID and Internet of Things implementations in logistics," in Quantifying the Value of RFID and the EPCglobal Architecture Framework in Logistics. New York, NY, USA: Springer-Verlag, 2012, pp. 71-100.

[15] P. Magrassi, T. Berg, A World of Smart Objects", Gartner research report R-17-2243, 12 August 2002.

[16] White Paper: Internet of Things Strategic Research Roadmap", Antoine de Saint-Exupery, 15 sep 2009.

[17] Souza, Alberto M.C. Amazonas, Jose R.A. A Novel Smart Home Application Using an Internet of Things Middleware", Proceedings of 2013 European Conference on Smart Objects, Systems and Technologies (SmartSysTech), pp. 1- 7, June 2013.

[18] Perumal, T, Ramli, A.R, Chui Yew Leong, Đesign and implementation of SOAP-based residential management for smart home systems", IEEE Transactions on Consumer Electronics, Vol: 54, pp. 453 - 459, May 2008.

[19] Jayavardhana Gubbi, Rajkumar Buyya, Slaven Marusic, Marimuthu Palaniswami, Internet of Things (IoT): A vision, architectural elements, and future directions", Elsavier - Future Generation Computer Systems, Vol.29, pp. 1645-1660, 2013.

[20]Chonggang Wang, Mahmoud Daneshmand, Mischa Dohler, Special Issue on Internet of Things (IoT):Architecture, Protocols and Services", IEEE Sensors Journal, Vol. 13, No. 10, October 2013.

[21] Louis Coetzee, Johan Eksteen, The Internet of Things Promise for the Future? An Introduction", IST-Africa Conference Proceedings, pp.1-9, 2011.

[22]K. Ashton, That Internet of Things“" thing, RFiD Journal (2009). [2] H. Sundmaeker, P. Guillemin, P. Friess, S. Woelfflé, Vision and challenges for realising the Internet of Things, Cluster of European Research Projects on the Internet of Things - CERP IoT, 2010.

[23] J. Buckley (Ed.), The Internet of Things: From RFID to the Next-Generation Pervasive Networked Systems, Auerbach Publications, New York, 2006.

[24]M. Weiser, R. Gold, The origins of ubiquitous computing research at PARC in the late 1980s, IBM Systems Journal (1999).

[25]Y. Rogers, Moving on from Weiser's vision of calm computing: engaging ubicomp experiences, in: UbiComp 2006: Ubiquitous Computing, 2006.

[26] A. Gluhak, S. Krco, M. Nati, D. Pfisterer, N. Mitton, T. Razafindralambo, A survey on facilities for experimental Internet of Things research, IEEE Communications Magazine 49 (2011) 58-67.

[27] L. Haiyan, C. Song, W. Dalei, N. Stergiou, S. Ka-Chun, A remote marker less human gait tracking for ehealthcare based on content-aware wireless multimedia

\section{Volume 5 Issue 2, February 2016}


communications, IEEE Wireless Communications 17 (2010) 44-50.

[28] G. Nussbaum, People with disabilities: assistive homes and environments, in: Computers Helping People with Special Needs, 2006.

[29]A. Alkar, U. Buhur, An Internet based wireless home automation system for multifunctional devices, IEEE Transactions on Consumer Electronics 51 (2005) 11691174.

[30] M. Darianian, M.P. Michael, Smart home mobile RFIDbased Internet-of- Things systems and services, in: 2008 International Conference on Advanced Computer Theory and Engineering, 2008, pp. 116-120.

[31] H.S. Ning, Z.O. Wang, Future Internet of Things architecture: like mankind neural system or social organization framework? IEEE Communications Letters 15 (2011) 461-463.

\section{Author Profile}

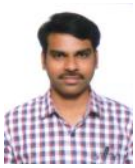

B.SobhanBabu M.Tech, working as Assistant Professor in Department of Information Technology, Gudlavalleru Engineering College, Gudlavalleru, AndhraPradesh.

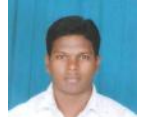

K. Srikanth M. Tech, working as Assistant Professor in Department of Information Technology, Gudlavalleru Engineering College, Gudlavalleru, Andhra Pradesh.

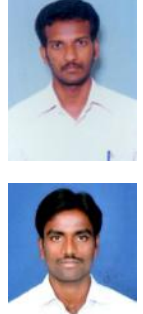

T. Ramanjaneyulu M. Tech, working as Assistant Professor in Department of Information Technology, Gudlavalleru Engineering College, Gudlavalleru, Andhra Pradesh.

I. Lakshmi Narayana M.Tech, working as Assistant Professor in Department of Information Technology, Gudlavalleru Engineering College, Gudlavalleru, AndhraPradesh. 